\title{
Шахин Э.
}

\section{ОТНОШЕНИЯ ТУРЦИИ И ЕВРОСОЮЗА НАКАНУНЕ САММИТА ЕС В ХЕАЬСИНКИ (АЕКАБРЬ 1999). КИПРСКАЯ ПРОБАЕМА И РЕЗУАЬТАТЫ САММИТА}

\begin{abstract}
Аннотация. В статье рассматривается развитие отношений между Туриией и Евросоюзом после саммита ЕС в Аюксембурге в декабре 1997 года и до саммита ЕС в Хельсинки в декабре 1999 года. Аля создания объективной картины автор кратко анализирует различные документы и доклады Саммитов ЕС, в которых обозначалась позиция сообщества по вопросам отночений с Туреикой республикой. Предметом исследования статьи служит эволюиия отношений между Турцией и ЕС в заданнысй период (декабрь 1997 - декабрь 1999 гг.). Объектом статьи являются политические аспекты определяющие характер этих взаимоотночений (Кипрский конфликт, решения изложенные в документах саммитов, позиция Греици, позииия США и т.д.). В качестве методологии исследования используется анализ. Автор анализирует отночения между Туриией и Евросоюзом. В статье также рассматриваются сопутствующие аспекты, которые определяют характер отночений между этими двумя политическими акторами. В качестве методологии автор также использует принцип историзма. Автор прослеживает возникновение и развитие рассматриваемых явлений с учетом конкретной исторической ситуации. Это позволяет рассмотреть процесс развития явлений в исторической ретроспективе. В заключении автор приходит к выводу, что Саммит ЕС в Хельсинки был поворотным событием для отночений Турции и ЕС. В заключительной декларачии председательства, принятой в коние Саммита, Туриия была названа страной-кандидатом на полноправное членство в Европейском Союзе. Такое развитие событий значительно уяучшило отношения между Турцией и сообществом. Позволило на тот момент преодолеть разногласия, созданнье решениями предьдущих Саммитов (в частности имеется в виду решение Саммита в Һюксембурге в 1997 году). Особым вкладом автора в исследование темы является то, ито он подробно анализирует решения и документы Саммитов ЕС, а также анализирует влияние этих решений на эволюиию отношений Турции и Евросоюза.
\end{abstract}

Ключевые слова: Европейский Союз, Европейская интеграчия, Туриия, Греиия, Кипрский конфликт, Северный Kunр, Кипр, Единая Европа, Растирение ЕС, ЕС.

Review. The article considers the development of relations between Turkey and the EU after the 1997 EU Luxembourg summit and until the 1999 Helsinki summit. To create an objective image, the author shortly analyses different documents and reports of the EU Summits that defined the position of the community regarding the relations with the Turkish republic. The subject of the article is th evolution of the EU-Turkish relations during the certain period (December 1997 December 1999). The object of the articles are the political aspects that define the nature of these relations (the Cyprus dispute, decisions published in the summit documents, position of Greece, position of the USA, etc.). Methodologically the research is based on analysis. The author analises EU-Turkish relations. The article also considers realted aspects that define the nature of relations between these two political actors. Methodologically the author relies on the principle of historicism. The author follows the emergence and development of the studied phenomena and events taking into account a certain historical situation. This allows to consider the development process in a historical retrospective. Finally, the author draws a conclusion that the Helsinki Summit was a pivotal point for the EU-Turkish relations. In the presidency conclusions adopted at the end of the Summit, Turkey was called a candidate country to become a full-fledged member of the EU. These developments significantly improved the relations between Turkey and the community. At that moment it allowed to overcome the divisions created by the decisions of the previous Summits (particularly the desicion of the Luxembourg Summit in 1997). A special author's contribution into the research is the fact that he in detal analyses decisions and documents of the EU Summits, and also analyses the impact of these desicions on the evolution of relations between Turkey and the European Union.

Keywords: Cyprus, Northern Cyprus, Cyprus Dispute, Greece, Turkey, European Integration, European Union, United Europe, EU Enlargement, EU. 
B начале XXI века, с одной стороны, происходит расширение Европейского Союза на Восток, с Аругой стороны, обсужАается вопрос о возможном присоединении Турции. В свою очередь Ава крупнейших государства Европы - Франция и Германия - выступали против присоединения Турецкой Республики. В качестве главного аргумента Париж и Берлин выАвигали разногласия межАу Турцией и Грецией по поводу Кипрского конфмикта. В этой связи в отношениях с Турцией Европейский Союз преАпочитает Аержать некую Аистанцию. Характер отношений межАу Турцией и ЕС отчетливо проявцялся на саммитах Евросоюза, а также в итоговых документах, разработанных в рамках этих саммитов.

16 июля 1997 года Комиссия ЕС публикует АоклаА ПоА заголовком «Повестка Аня - 2000». В Аокладе, в частности, была изможена Аальнейшая стратегия по расширению Союза. ГАавным образом в докладе оговаривались условия расширения Евросоюза за счет стран Восточной Европы. А также, в частности, говорилось, что в краткосрочной перспективе греческая часть Кипра Аолжна будет стать полноправным членом Европейского союза.

12-13 декабря 1997 года на саммите ЕС в Аюксембурге был принят закмючитемьный докмаА, большая часть которого была посвящена вопросу расширения Евросоюза. Амя Турции этот докмаА имем

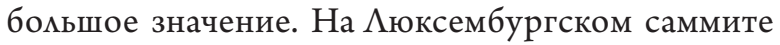
Турция не была указана среди стран-кандидатов на присоединение к ЕС. Такая позиция сообщества еще больше усложнила отношения межАу ЕС и Турцией.

Расширение ЕС предполагалось осуществлять в Аве стадии. В результате на первой стаАии расширения 1 мая 2004 года в ЕС вступили такие государства, как Польша, Венгрия, Чехия, Словения, Словакия, Эстония, Аатвия, Аитва, Мальта и Кипр (греческая часть острова). Эти страны в наибольшей степени соответствовали «Копенгагенским критериям». Эти критерии были приняты еще в июне 1993 года на заседании Европейского совета в Копенгагене. Среди критериев были такие требования, как демократическая форма правмения, соблюдение прав человека, верховенство закона, уважение и защита прав меньшинств и Ар.

На второй стадии расширения к ЕС присоединились страны, которые в меньшей степени соответствовали «Копенгагенским критериям» - Румыния и Болгария. Турция, соответственно, осталась вне Союза.

После доклада, принятого на Аюксембургском саммите тогАашний премьер-министр Турции Ме- сут Йыммаз (Mesut Yilmaz) на пресс-конференции 14 декабря 1997 года заявик о том, что позиция ЕС по отношению к его стране явмяется преАвзятой. Он также подчеркнул, что в случае, если Евросоюз не изменит свою позицию, такое положение Аел будет препятствовать развитию конструктивного и многогранного Аиалога в отношениях Турция ЕС. В заявлении также бымо отмечено, что в такой ситуации будет ускорена интеграция с Северной Кипром ${ }^{[1]}$.

4 марта 1998 года Европейская Комиссия поАготовила докмаА, в котором была изможена Аальнейшая стратегия отношений с Турцией, а также политические рекоменАации Амя самой Турции ${ }^{[2]}$. Отмечалось, что в скучае реализации изложенных в докладе рекомендаций, Турция будет вовлечена в процесс расширения ЕС. Тем самым планировамось снизить уровень неАовольства Анкары и удовметворить ее требования относительно процесса интеграции с ЕС. В Аокмаде также были изможены обязательства ЕС в вопросах финансового сотруАничества с Турцией ${ }^{[3]}$.

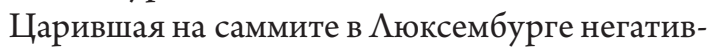
ная атмосфера привела к ухудшению Авусторонних отношений межАу Турцией и ЕС. Поэтому, с целью смягчить ситуацию, 15-16 июня 1998 гоАа на саммите в Кардиффе ЕС Аобавил Турцию в список странкандидатов на вступиение в ЕС ${ }^{[4]}$. Выражение «право на членство» в отношении Турции в документе было заменено на «кандидат на присоединение».

На саммите в Вене 11-12 декабря 1998 года была отмечена важность продолжения развития сотрудничества между Евросоюзом и ЕС.

Анализируя все саммиты, можно прийти к выводу, что препятствия на пути присоединения Турции к ЕС в большей степени имели не экономический, а политический характер ${ }^{[5]}$.

\section{ВАИЯНИЕ КИПРСКОЙ ПРОБАЕМЫ НА ОТНОШЕНИЯ ТУРЦИЯ-ЕС}

Накануне саммита ЕС в Хельсинки отношения межАу Турецкой Республикой и Европейским Союзом переживают чрезвычайно важный этап. В Аокладе Комиссии ЕС 13 октября 1999 года Турцию называют «страной кандидатом» на полноправное членство. ОАнако Аля начала преАметных переговоров Турции необходимо бымо решить ряА задач национального масштаба. Такими задачами были названы: отмена смертной казни, ускорение процесса демократизации, усовершенствование политики по отношению к национацьным и иным меньшинствам, принятие некоторых экономических и социальных мер. В этой связи Комиссия ЕС 
составила Аля Турции «дорожную карту». Также в Аокладе была еще раз озвучена необходимость соответствия Копенгагенским критериям. Без этого Аальнейший процесс интеграции преАставцялся невозможным.

В декабре 1999 года проходит саммит ЕС в Хемьсинки. В рамках саммита быц подготовлен АоклаА Комиссии, посвященный взаимоотношениям Турции и ЕС. В Аокладе Комиссии, состоявшем из 58 страниц, отмечались плодотворная работа таможенного союза, значительный прогресс экономики Турции - в частности, в вопросе эффективного функционирования свободного рынка. Также в Аокиаде бымо заявмено о необходимости возобновмения политического Аиалога, который быц приостановлен после момент АоклаА сыграц важную роль в сближении Турции с Европейским Союзом.

ОАнако стоит сказать и о факторах, подтолкнувших ЕС на установление Аиалога с Турцией. Кипрский конфмикт созАавац множество политических и правовых неопреАеленностей, которые препятствовали процессу Аахьнейшей интеграции Кипра и ЕС. НезаАолго Ао этого стало понятно, что без вмешательства турецкой стороны, переговоры с Южный Кипром о присоеАинении к Евросоюзу заходят в тупик. В то же время Турция после решений Аюксембургского саммита 1997 года чувствоваца себя в политической изоляции и поэтому приняла решение не обсужАать с ЕС политические вопросы, в том числе, и кипрскую пробкему.

В резумьтате такого решения ЕС утратил возможность оказывать Аавление на Турцию по ряду вопросов. Следовательно, Аля Евросоюза было могичным сАелать такой шаг, который способствовац бы налаживанию политического Аиалога с Турцией. Турция, в свою очереАь, имема вмияние на Северный Кипр и могла сАелать вклаА в решение конфликта на острове, что способствовало бы ускорению интеграции послеАнего с ЕС. В этот периоА Аля Турции официальное присвоение статуса «страны кандидата» являлось важным политическим шагом. В то же время, если обратить внимание на новую политику ЕС, впервые союз не навязывал Турции что-либо, а Аобивался результатов «мягкими высказываниями».

Ао саммита в Хемьсинки, переговоры о вступлении межАу греческими властями Южного Кипра и ЕС начамись в марте 1998 года. Аля Турции это было неприемлемым и нежелательным развитием событий. Ситуация усугублялась еще и тем, что в июне 1997 года Комиссия ЕС исключила Турцию из списка кандидатов на расширение первой волны ${ }^{[6]}$.
Кипрская проблема становилась головной бомью Аля Европейского Союза. С оАной стороны, Греция угрожала наложить вето на решения Еврокомиссии, если послеАняя не примет никаких мер по вступлению Кипра в ЕС. С Аругой стороны, Турция угрожама развивать интеграцию с Северным Кипром ${ }^{[7]}$. Развитие политической ситуации привело к тому, что споры в Эгейском регионе и на Кипре вышли за рамки Авусторонних отношений и превратились в общую проблему Европейского Союза. И если раньше чиенство в ЕС было Аля Турции целью, то теперь это стало среАством решения вышеуказанных споров. Более того, кипрский конфликт и споры в Эгейском регионе превратились в вопросы внутренней политики как Аля Турции, так и Амя Греции.

На саммите в Хемьсинки ЕС уАалось снизить напряжение, возникшее в отношениях с Турцией

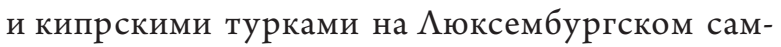
мите.

В этой ситуации США также оказывами влияние на развитие отношений межАу Турцией и Евросоюзом. По мнению США, кипрскую проблему следовало решать путем устранения греко-турецких разногласий. Согласно позиции Штатов, Аля решения кипрской проблемы немаловажным было подАержать стремление Турции присоеАиниться к Евросоюзу ${ }^{[8]}$.

В свою очереАь Греция заявмяла, что не будет препятствовать объявлению Турции в качестве канАиАата на присоединение только тогАа, когАа Европейский совет объявит, что Аля вступления Кипра в ЕС больше нет никаких препятствий ${ }^{[9]}$.

В свою очереАь Греция также влияла на процесс переговоров межАу Турцией и ЕС и всячески выражала свою позицию по Аанному вопросу.

ПереА саммитом в Хемьсинки Греция обнароАовала меморандум, гАе были заявлены слеАующие условия:

1. Решение кипрской проблемы не Аолжно препятствовать полноправному членству Кипрской Респубмики в ЕС;

2. Аюбое госуаарство, явмяющееся канАиАатом на чиенство ЕС, Аолжно Ао определенного срока (примерно Ао конца 2000 года) признать юрисаикцию МежАународного СуАа. Этому УАелено внимание и в Повестке- 2000, но в Аанный момент это юридически не обосновано;

3. Правительство Греции хотело видеть статус канАилата Аля Турции как реальную возможность. Аругими словами, Аля Турции должна была быть состав ена «дорожная карта», содержащая права и ответственности кандиАата ${ }^{[10]}$. 
Условия, указанные Грецией, в значительной степени отразились в итоговом документе саммита в Хемьсинки.

\section{ЗАКАЮЧЕНИЕ}

Саммит глав государств и правительств, провеАенный в Хельсинки в Аекабре 1999 года во время преАседательства Финцяндии, явился поворотным событием в истории отношений Турции с ЕС. В заключительной Аекларации преАсеАательства, принятой в конце саммита, Турция была названа страной-кандидатом на полноправное чценство в Европейском Союзе.

Чтобы дойти до этой точки Турции потребовамось немало усилий. За Ава года Ао этого в декабре 1997 года на саммите в ряА «политических ошибок» со стороны ЕС. После саммита в Аелялся слеАующими факторами:

- Сразу после саммита политический Аиалог с Турцией был фактически прекращен;

- Имел место застой в начатых переговорах межАу ЕС и греческими властями Южного Кипра о полноправном чиенстве. Позже ЕС приходит к пониманию, что признание Южного Кипра в качестве полноправного чиена под общим названием «Республика Кипр» стало причиной возникновения политических и правовых проблем. ЕС признает, что Аля решения кипрской проблемы необходим диалог с Турцией;

- Увеличивается «геополитическое значение» Турции в связи с политическими и военными столкновениями на ее территории;

- Премьер-министр ЭАжевит делает заявление, что к сереАине 1999 года социально-экономическая и политическая система Турции будут соответствовать «Копенгагенским критериям», в скучае присвоения ей статуса страныкандидата;

- В рамках ЕС приходит осознание того, что без участия Турции могут возникнуть серьезные трудности при реализации общей европейской помитики обороны и безопасности;
- Парамлельно имеет место политическое давление президента США Клинтона на ЕС в вопросах взаимоотношений с Турцией и кипрского конфмикта;

- Стратегическая значимость партнерства с Турцией увеличивалась еще и в связи со сближением России и Китая. В этой ситуации в ЕС осознают, что Турцию нельзя оставцять в состоянии политической изоляции;

- В этот период увеличивается вероятность прокладки трубопровода Баку-Ажейхан через территорию Турции и оАновременно растет вАияние этого события на политическую и экономическую стабильность в регионе Ближнего Востока;

- Накануне саммита в Хемьсинки в Турции имеет место интенсивное моббирование ассоциации Турция-ЕС. Организации гражАанского общества и бизнес высказываются в пользу вступления в ЕС ${ }^{[11]}$.

В связи с вышеуказанными причинами на саммите в Хемьсинки Турция была еАиногласно принята в страны-кандидаты на полноправное членство в ЕС. Во время саммита в Хемьсинки, впервые в истории $\mathrm{EC}$, верховный комиссар ЕС Солона и ответственный чмен Комиссии по расширению Ферхойген прибыли на несколько часов в Анкару с визитом, чтобы успокоить турецкое правительство, в особенности по вопросам Кипра и Эгейского региона. ВслеА за этим премьер-министр ЭАжевит, министр иностранных Аел Ажем, а также министр по вопросам ЕС Иртемчелик посетили Хельсинки, а на второй Аень саммита Турция заняла свое место на знаменитом «семейном фото» ЕС ${ }^{[12]}$. За Ава года после саммита в Аюксембурге Авусторонние отношения межАУ ТУрцией и ЕС прохоАят эволюцию от полного охлаждения Ао существенного улучшения и установцения эффективного политического Аиалога. В результате саммита в Хемьсинки отношения Турции и ЕС улучшаются. ПравАа, стоит отметить, что Турция и по сей Аень не явмяется членом Европейского Союза, и реацьных перспектив ее вступления в сообщество пока не преАвиАится.

\section{БИБАИОГРАФИЯ}

1. Yilmaz on EU, Cyprus, Greece // Interesting Nodes of EU Member Governments, Politics \& Mass Media (URL: http://www.hri.org/news/cyprus/tcpr/1997/97-12-29.tcpr.html).

2. Regular Report From The Commission on Turkey's Progress Towards Accession // EUROPEAN COMMISSION (URL: http://ec.europa.eu/enlargement/archives/pdf/key_documents/1998/turkey_ en.pdf).

3. Türkiye Düzenli İlerleme Raporu 1998 // Türkiye Cumhuriyeti. Avrupa Birliği Bakanlığ1 (URL: http:// www.abgs.gov.tr/files/AB_Iliskileri/AdaylikSureci/IlerlemeRaporlari/ Turkiye_Ilerleme_Rap_1998. pdf). 
4. Cardiff European Council. 15 and 16 June 1998. Presidency Conclusions // European Council Council of the European Union (URL: http://www.consilium.europa.eu/uedocs/cms_data/docs/pressdata/en/ ec/54315.pdf).

5. Bozkurt E., Havva demirel, Birleşmiş Milletler ve Avrupa Birliği Kapsamında Kıbrıs Sorunu, 2004, Nobel yayin, S.178.

6. Christou G. The European Union and Enlargement. The Case of Cyprus. Palgrave Macmillan, London, 2004, P. 75.

7. Bahcheli T. The Lure of Economic Prosperity Versus Ethno-Nationalism: Turkish Cypriots, the European Union Option, and the Resolution of Ethnic Conflict in Cyprus, Oxford Scholarship Online, Oxford, 2003, P. 14.

8. Attalides M., The Cyprus Problem after the 1999 Helsinki, Mediterranean Quarterly, Volume 25, Number 1, Winter 2014, P. 27.

9. Sepos A., The Europeanization of Cyprus, Polity, Policies and Politics, Palgrave Macmillan, New York, 2008, P. 44.

10. Aksu F., Ege ve Kıbrıs Sorunlarının Çözümünde Avrupa Birliği’nin Tutumu, Stratejik Araştırmalar Dergisi, Yil 2, Sayı 3, Şubat 2004, P. 110.

11. Larrabee F. S., Lesser I. O., Turkish Foreign Policy in Age of Uncertainty // RAND Corporation. Objective Analysis. Effective Solutions (URL: http://www.rand.org/content/dam/rand/pubs/monograph_reports/ MR1612/MR1612.pref.pdf).

12. Günuğur H., Türkiye-Avrupa Birliği İlişkileri, Avrupa Ekonomik Danışma Merkezi Yayınevi, Ankara, 2007, ss. $160-161$

\section{REFERENCES (TRANSLITERATED)}

1. Yilmaz on EU, Cyprus, Greece // Interesting Nodes of EU Member Governments, Politics \& Mass Media (URL: http://www.hri.org/news/cyprus/tcpr/1997/97-12-29.tcpr.html).

2. Regular Report From The Commission on Turkey's Progress Towards Accession // EUROPEAN COMMISSION (URL: http://ec.europa.eu/enlargement/archives/pdf/key_documents/1998/turkey_ en.pdf).

3. Türkiye Düzenli İlerleme Raporu 1998 // Türkiye Cumhuriyeti. Avrupa Birliği Bakanlı̆ğ (URL: http:// www.abgs.gov.tr/files/AB_Iliskileri/AdaylikSureci/IlerlemeRaporlari/Turkiye_Ilerleme_Rap_1998.pdf).

4. Cardiff European Council. 15 and 16 June 1998. Presidency Conclusions // European Council Council of the European Union (URL: http://www.consilium.europa.eu/uedocs/cms_data/docs/pressdata/en/ ec/54315.pdf).

5. Bozkurt E., Havva demirel, Birleşmiş Milletler ve Avrupa Birliği Kapsamında Kıbrıs Sorunu, 2004, Nobel yayin, S.178.

6. Christou G. The European Union and Enlargement. The Case of Cyprus. Palgrave Macmillan, London, 2004, P. 75.

7. Bahcheli T. The Lure of Economic Prosperity Versus Ethno-Nationalism: Turkish Cypriots, the European Union Option, and the Resolution of Ethnic Conflict in Cyprus, Oxford Scholarship Online, Oxford, 2003, P. 14.

8. Attalides M., The Cyprus Problem after the 1999 Helsinki, Mediterranean Quarterly, Volume 25, Number 1, Winter 2014, P. 27.

9. Sepos A., The Europeanization of Cyprus, Polity, Policies and Politics, Palgrave Macmillan, New York, 2008, P. 44.

10. Aksu F., Ege ve Kıbrıs Sorunlarının Çözümünde Avrupa Birliği’nin Tutumu, Stratejik Araştırmalar Dergisi, Yıl 2, Sayı 3, Şubat 2004, P. 110.

11. Larrabee F. S., Lesser I. O., Turkish Foreign Policy in Age of Uncertainty // RAND Corporation. Objective Analysis. Effective Solutions (URL: http://www.rand.org/content/dam/rand/pubs/monograph_reports/ MR1612/MR1612.pref.pdf).

12. Günuğur H., Türkiye-Avrupa Birliği İlişkileri, Avrupa Ekonomik Danışma Merkezi Yayınevi, Ankara, 2007, ss. $160-161$ 